\title{
Влияние наличия достаточно высокой концентрации фосфора на концентрационное распределение галлия в кремнии
}

\author{
(C) М.К. Бахадирханов, Н.Ф. Зикриллаев, С.Б. Исамов, Х.С. Турекеев, С.А. Валиев \\ Ташкентский государственный технический университет, \\ 100095 Ташкент, Узбекистан \\ E-mail: bahazeb@yandex.ru
}

Поступила в Редакцию 9 апреля 2021 г.

В окончательной редакции 11 сентября 2021 г.

Принята к публикации 20 сентября 2021 г.

\begin{abstract}
Установлено, что в кремнии, предварительно легированном высокой концентрацией фосфора, при диффузии галлия происходит существенное увеличение растворимости галлия. Полученные результаты объясняются взаимодействием атомов галлия и фосфора, в результате которого формируются квазинейтральные молекулы $\left[\mathrm{P}^{+} \mathrm{Ga}^{-}\right]$. Предполагается, что образование таких квазинейтральных молекул $\left[\mathrm{P}^{+} \mathrm{Ga}^{-}\right]$стимулирует формирование бинарных элементарных ячеек $\mathrm{Si}_{2} \mathrm{GaP}$ в решетке кремния. Показано, что достаточно большая концентрация таких элементарных ячеек может привести к существенному изменению электрофизических параметров кремния и к возможности получения нового материала на основе кремния.
\end{abstract}

Ключевые слова: кремний, легирование, фосфор, галлий, диффузия.

DOI: 10.21883/FTP.2022.02.51962.9666

\section{1. Введение}

Взаимодействие примесных атомов между собой в кристаллической решетке представляет собой особый научный и практический интерес. Благодаря таким взаимодействиям стимулируется формирование различных видов моноатомных нано- и микрокластеров $[1-3]$, на основе которых возможно создание объемно наноструктурированных полупроводниковых материалов, которые практически невозможно получить другими технологическими методами. Кластеры примесных атомов с различной природой (электронейтральные, магнитные, многозарядные и т.д.) позволяют получить материал с уникальными электрофизическими параметрами и функциональными возможностями [4-7].

Исследование взаимодействия элементов III и V групп в решетке кремния представляет большой интерес. Во-первых, в результате таких взаимодействий можно формировать бинарные нанокластеры с различным составом, структурой и природой; во-вторых, благодаря очень высокой растворимости элементов III и V групп $\left(N \geq 10^{20}-10^{21} \mathrm{~cm}^{-3}\right)$ возможно создание бинарных кластеров с достаточно высокой концентрацией, которые могут существенно влиять на энергетическую структуру кремния. Наконец, в-третьих, из-за достаточно низкого коэффициента диффузии этих элементов в кремнии $\left(D \sim 10^{-12}-10^{-13} \mathrm{~cm}^{2} / \mathrm{c}\right)$ удается формировать бинарные кластеры как в приповерхностной области, так и в объеме кристалла с необходимой толщиной [8-10].

Поэтому цель данной работы заключалась в изучении взаимодействия атомов фосфора $(\mathrm{P})$ и галлия $(\mathrm{Ga})$ в кремнии при последовательной диффузии этих примесей.

\section{2. Технология изготовления образцов и методы их исследования}

В качестве исходного материала был использован монокристаллический кремний КЭФ-100 $\left(N_{P} \sim 10^{13} \mathrm{~cm}^{-3}\right)$ с содержанием кислорода $N_{\mathrm{O}_{2}} \approx(5-6) \cdot 10^{17} \mathrm{~cm}^{-3}$ и плотностью дислокаций $N_{D} \sim 10^{3} \mathrm{~cm}^{-2}$. Размер образцов составлял $V \sim 1 \times 4 \times 8$ мм. После необходимых механических и химических обработок образцов проводилась диффузия фосфора из нанесенного слоя фосфорнокислого аммония на воздухе при $T=1000^{\circ} \mathrm{C}$ в течение $t=2$ ч. После диффузии во всех образцах снималось с поверхности фосфоросиликатное стекло методом травления на $\mathrm{HF}$ и $\mathrm{NH}_{4} \mathrm{~F}$. При этом концентрация фосфора на поверхности образцов составляла $N_{\mathrm{P}}=2 \cdot 10^{20} \mathrm{~cm}^{-3}$.

Диффузия галлия в кремнии (КЭФ-100) проводилась из газовой фазы при температуре $T=1250^{\circ} \mathrm{C}$ в течение 4 ч. Такой выбор условий диффузии галлия диктовался тем, чтобы получить максимальную концентрацию на поверхности и в объеме кремния.

Затем в образцах, легированным фосфором, проводилась диффузия галлия при $T=1250^{\circ} \mathrm{C}$ в течение 4 ч. При этом одновременно подвергались термоотжигу образцы кремния, легированного фосфором (без галлия), также при $T=1250^{\circ} \mathrm{C}, t=4$ ч, чтобы определить изменение концентрационного распределения фосфора при дополнительных отжигах.

Таким образом, получилось 4 партии образцов: I - образцы после диффузия фосфора при $T=1000^{\circ} \mathrm{C}, t=2$ ч; II - образцы, легированные галлием при $T=1250^{\circ} \mathrm{C}$, $t=4$ ч, которые предварительно легировались фосфором при $T=1000^{\circ} \mathrm{C}, t=2$ ч; III - контрольные образцы, легированные фосфором $\left(T=1000^{\circ} \mathrm{C}, t=2\right.$ ч), отожженные при $T=1250^{\circ} \mathrm{C}, t=4 \mathrm{q} ; \mathrm{IV}-$ контрольные 
образцы, легированные только галлием при $T=1250^{\circ} \mathrm{C}$, $t=4$ ч, в которых не проводилась диффузия фосфора.

Концентрационное распределение снималось с помощью 4-зондового метода послойным снятием слоя по 1 мкм методом химического травления. При этом предполагалось, что все введенные примесные атомы фосфора и галлия находятся в электрически активном состоянии. При расчете концентрации фосфора и галлия (электронов и дырок) учитывалось изменение подвижности носителей заряда от концентрации примесных атомов [11]. Ошибка измерения не превышала 10\%.

\section{3. Результаты исследования}

На рис. 1 представлено концентрационное распределение атомов фосфора в кремнии после диффузии $T=1000^{\circ} \mathrm{C}, t=2$ ч. Также на рисунке представлено концентрационное распределение галлия после диффузии при $T=1250^{\circ} \mathrm{C}, t=4$ ч в образцах КЭФ-100. Как видно из экспериментальных результатов, концентрация фосфора в приповерхностной области составляет $N_{\mathrm{P}}=2 \cdot 10^{20} \mathrm{~cm}^{-3}$, а на глубине $x=2.5$ мкм его концентрация уменьшается до $\sim 10^{14} \mathrm{~cm}^{-3}$ (кривая 1), при этом образцы все время остаются $n$-типа. Это полностью соответствует литературным данным [12-14].

В то же время поверхностная концентрация галлия после диффузии при $T=1250^{\circ} \mathrm{C}, t=4$ ч достигает $4 \cdot 10^{19} \mathrm{~cm}^{-3}$, она монотонно уменьшается на глубине образца и при $x=25$ мкм составляет $\sim 10^{14} \mathrm{~cm}^{-3}$. Установлено, что при этом в области распределения галлия

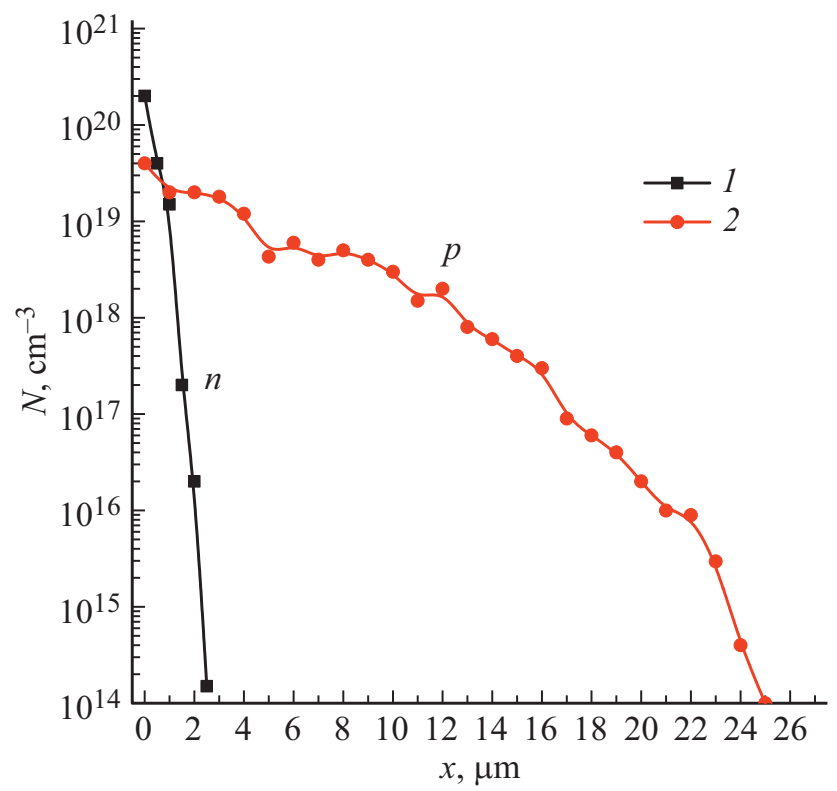

Рис. 1. Концентрационное распределение электронов (атомов фосфора) и дырок (галлия) в решетке кремния, диффундированных независимо друг от друга: 1 - распределение электронов (фосфора) при $T=1000^{\circ} \mathrm{C}, t=2$ ч; $2-$ распределение дырок (галлия) при $T=1250^{\circ} \mathrm{C}, t=4$ ч.

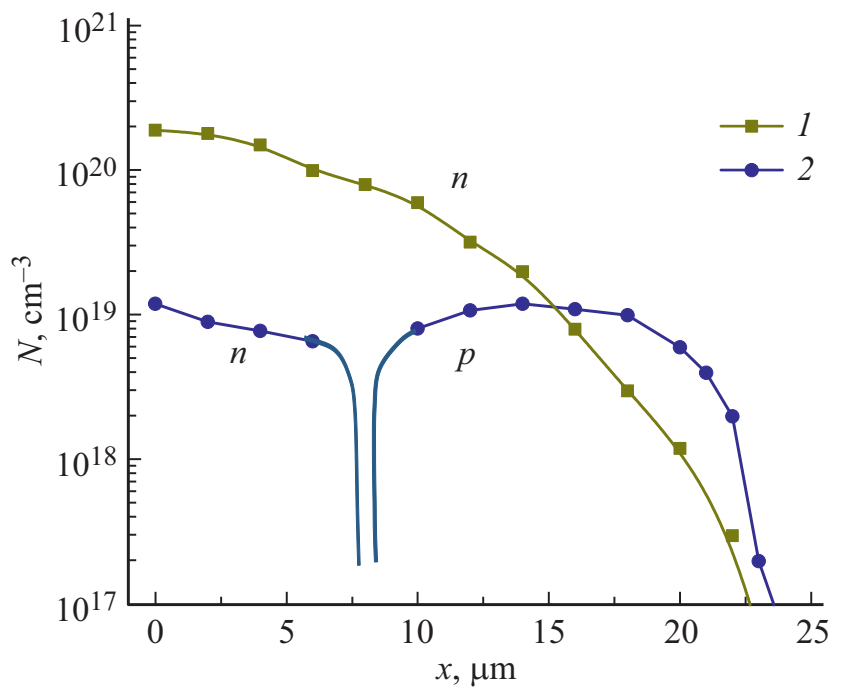

Рис. 2. Концентрационное распределение электронов (фосфора) в образцах, дополнительно отожженных при $T=1250^{\circ} \mathrm{C}$, $t=4$ ч (кривая 1$)$; концентрационное распределение носителей заряда в образцах, легированных галлием, предварительно легированных фосфором (кривая 2). $n$ - и $p$-тип проводимости образцов при данной глубине.

образцы остаются p-типа. Эти данные также подтверждают работы $[15,16]$. Таким образом, концентрационное распределение фосфора и галлия при их диффузии существенно отличаются друг от друга.

На рис. 2 представлены концентрационное распределение фосфора в контрольных образцах, которые подвергались дополнительному термоотжигу при $T=1250^{\circ} \mathrm{C}$, $t=4$ ч (кривая 1 ), а также концентрационное распределение носителей заряда в образцах кремния, легированных галлием при $T=1250^{\circ} \mathrm{C}, t=4$ ч, которые были предварительно легированы фосфором при $1000^{\circ} \mathrm{C}$, $t=2$ ч (кривая 2). Как видно из рисунка, в результате дополнительного отжига при $T=1250^{\circ} \mathrm{C}, t=4$ ч поверхностная концентрация фосфора незначительно уменьшается, а глубина проникновения достигает $x=25$ мкм (кривая 1 ), в области $x=0-25$ мкм образцы приобретают $n$-тип проводимости.

Концентрационное распределение в образцах, легированных галлием при $t=1250^{\circ} \mathrm{C}, t=4$ ч, после легирования фосфором при $1000^{\circ} \mathrm{C}, t=2 F$ ч (кривая 2) показывает, что в исследуемых образцах до глубины $x=7.5-8$ мкм имеется $n$-тип проводимости. При этом концентрация электронов (фосфора) уменьшается, а при $x>7.5-8$ мкм образцы приобретают $p$-тип проводимости. В области $x=7.5-10$ мкм концентрация дырок незначительно увеличивается, в области $x=8-15$ мкм концентрация дырок (галлия) практически остается постоянной, а при $x>17$ мкм достаточно резко уменьшается. Практически во всех образцах получается аналогичный результат. Эти результаты показывают, что при диффузии галлия (при наличии высокой концентрации фосфора) концентрация фосфора в области 


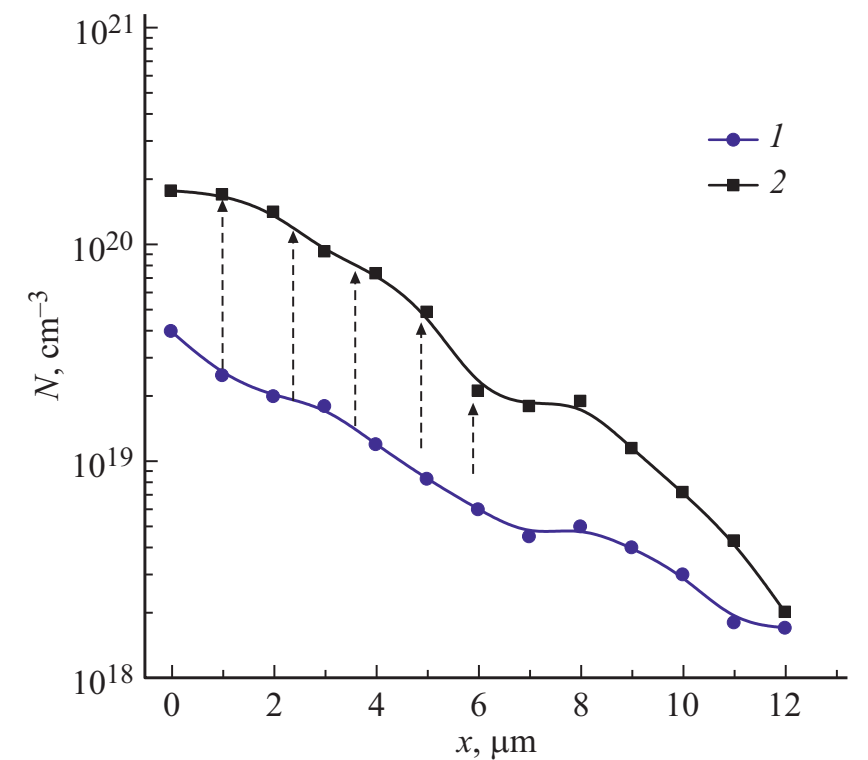

Рис. 3. Концентрационное распределение дырок (галлия) при отсутствии (кривая 1) и при наличии (кривая 2) фосфора.

$x=0-7.5$ мкм уменьшается на $1-1.5$ порядка, затем концентрация галлия становится больше, чем концентрация фосфора, и материал обладает $p$-типом проводимости. Хотя, как видно из рис. 2 (кривая 1), концентрация фосфора до области 15 мкм больше, чем концентрация галлия. Эти результаты дают возможность предполагать, что наличие фосфора в кремнии приводит к повышению концентрации галлия. На основе полученных результатов (см. рис. 2, кривые 1 и 2) вычислялось значение концентрации галлия по глубине образца при наличии фосфора. Расчет проводился исходя из уравнения нейтральности $N_{\mathrm{Ga}}=n_{0}-n_{1}$ в области $x=0-7.5$ мкм, где $n_{0}$ - концентрация электронов в образцах, легированных фосфором, отожженных дополнительно при $T=1250^{\circ} \mathrm{C}, t=4$ ч, $n_{1}-$ концентрация электронов в образцах, легированных галлием при наличии фосфора, а в области $x>7.5$ мкм. $N_{\mathrm{Ga}}=n_{2}+p$, где $n_{2}$ - концентрация электронов в образцах кремния, легированных фосфором и отожженных при $T=1250^{\circ} \mathrm{C}, t=4$ ч, в данной области $x, p-$ концентрация дырок в этой области.

На рис. 3 представлены концентрационное распределение атомов галлия при диффузии $T=1250^{\circ} \mathrm{C}, t=4$ ч в отсутствие диффузии фосфора, а также расчетное концентрационное распределение атомов галлия при таких же условиях диффузии в образцах, которые были предварительно легированы фосфором при $1000^{\circ} \mathrm{C}$, $t=2$ ч. Из этих результатов следует, что независимо от одинаковых условий диффузионного легирования во всех материалах концентрационное распределение атомов галлия в 4-6 раз больше в образцах, дополнительно легированных фосфором, чем в образцах без фосфора. Это означает, что наличие достаточно высокой концентрации фосфора существенно увеличивает растворимость атомов галлия. Также следует отметить, что глубина залегания галлия в образцах, легированных фосфором, меньше (2-3 мкм), чем в образцах без фосфора. Полученные экспериментальные данные частично подтверждают результаты работ $[17,18]$, несмотря на то что там исследовалось взаимодействие фосфора с бором.

\section{4. Обсуждение результатов}

Полученные экспериментальные результаты невозможно объяснить взаимной компенсацией донорных (фосфор) и акцепторных (галлий) примесных атомов. При этом атомы фосфора и галлия в решетке кремния распределены хаотически, и эти атомы пространственно разделены. Это не должно приводить к повышению концентрации атомов галлия при наличии атомов фосфора. Поэтому можно предполагать, что это явление связано с взаимодействием атомов фосфора и галлия. Так как атомы фосфора в решетке кремния находятся в узлах кристаллической решетки в виде положительно заряженного иона $\mathrm{P}^{+}$, создавая дополнительные электроны в зоне проводимости, значение которого равно $\mathrm{NP}^{+}$. Наличие достаточно большой концентрации положительно заряженных атомов фосфора $\left(\mathrm{P}^{+}\right)$практически создает электрические потенциалы, распределенные от поверхности кристалла по глубине образца в кремнии, что стимулирует повышение атомов галлия в процессе диффузии, которые в кремнии действуют как акцепторная примесь в виде отрицательного иона $\mathrm{Ga}^{-}$. Поэтому можно предполагать, что в результате таких взаимодействий в решетке кремния появляются донорно-акцепторные комплексы, т.е. квазимолекулы в виде $\left[\mathrm{P}^{+} \mathrm{Ga}^{-}\right]$.

Такие комплексы могут существовать только в случаях, когда атомы фосфора и галлия находятся рядом, т. е. они занимают соседние два узла в решетке кремния (рис. 4,a). Другое положение атомов галлия и фосфора в решетке кремния не обеспечивает стабильного образования комплексов между этими примесными атомами. Образование таких электрически нейтральных комплексов $\left[\mathrm{P}^{+} \mathrm{Ga}^{-}\right]$приводит систему к более выгодному термодинамическому состоянию, чем в случае, когда атомы этих примесей удалены друг от друга. При образовании комплексов, во-первых, существенно уменьшается концентрация носителей заряда как в зоне проводимости, так и в валентной зоне, т.е. степень дефектности кристалла уменьшается; во-вторых, электрические потенциалы, которые создаются вокруг каждого иона, экранируются между собой, что опять приводит к понижению степени дефектности кристалла.

Все эти факторы стимулируют образование комплексов $\left[\mathrm{P}^{+} \mathrm{Ga}^{-}\right]$, так как наличие достаточно высокой концентрации фосфора в кремнии создает более благоприятные условия для повышения концентрации вновь диффундирующих атомов галлия. Доказательством этого предположения служат следующие результаты иссле- 


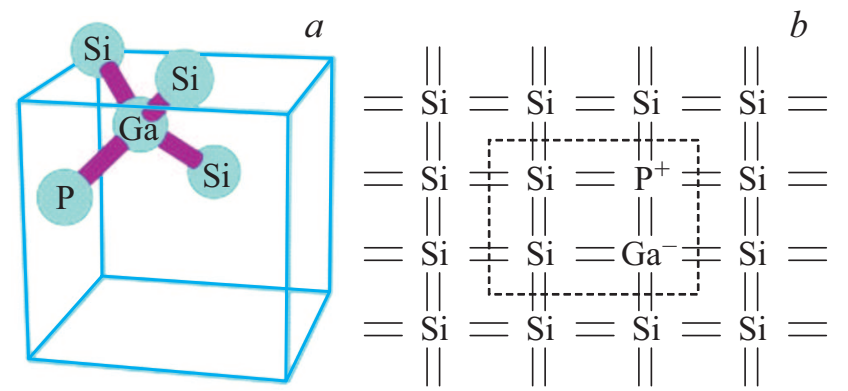

Рис. 4. Квазимолекулы $\mathrm{Ga}-\mathrm{P}^{+}(a)$, бинарные электронейтральные решетки типа $\mathrm{Si}_{2} \mathrm{P}^{+} \mathrm{Ga}^{-}$в кремнии $(b)$.

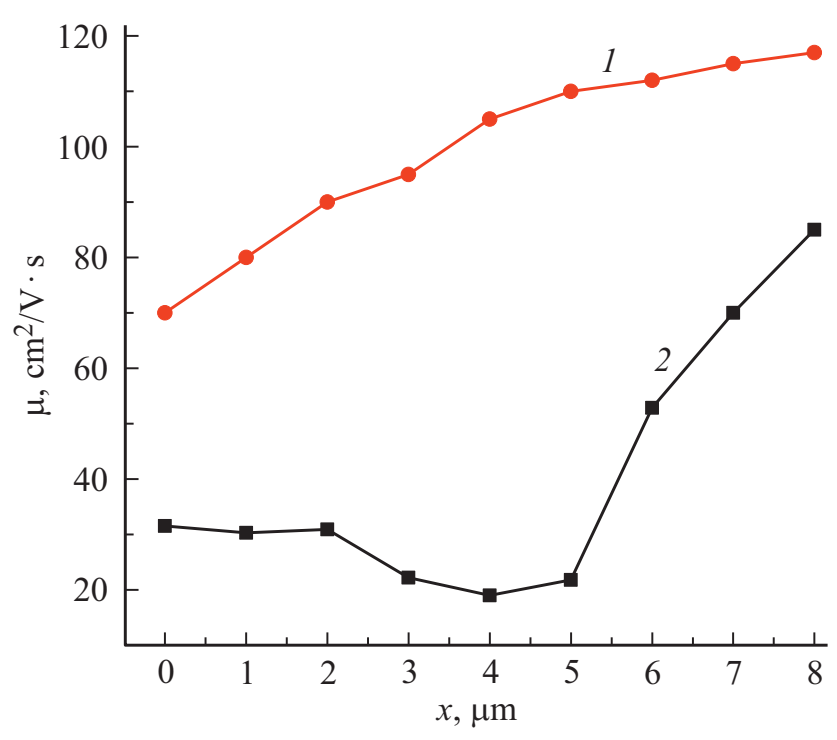

Рис. 5. Изменение подвижности электронов в кремнии, легированном фосфором (1), и в кремнии (предварительно легированном фосфором), легированном галлием (2).

дования. Была проведена диффузия галлия в кремнии при $T=1250^{\circ} \mathrm{C}$ в течение $t=4$ ч, но с поверхностной концентрацией фосфора $N_{\mathrm{P}} \sim 10^{17} \mathrm{~cm}^{-3}$, т.е. значительно меньше, чем растворимость галлия при данной темпертуре. Такие образцы были получены шлифовкой поверхности кремния, легированного фосфором при $1000^{\circ} \mathrm{C}, t=2$ ч, а затем отожженые при температуре $T=1250^{\circ} \mathrm{C}, t=4$ ч. Как показали результаты экспериментов, в этом случае никакого повышения растворимости атомов галлия не было обнаружено. В результате исследования было установлено, что заметное повышение растворимости галлия происходит только тогда, когда концентрация атомов фосфора $N_{\mathrm{P}} \geq N_{\mathrm{Ga}}$.

Таким образом, можно утверждать, что повышение растворимости атомов галлия в кремнии с повышенной концентрацией фосфора связано с образованием комплексов в виде электрически нейтральных молекул в решетке кремния. Подтверждением этого могут служить результаты исследования подвижности носителей заряда по толщине образца методом Ван-дер-Пау (рис. 5). Как видно из рисунка, несмотря на то что до 8 мкм образцы кремния (предварительно легированного фосфором), легированного галлием и кремния, легированного фосфором без галлия, имеют $n$-тип проводимости, но подвижность электронов в кремнии с комплексами $[\mathrm{GaP}]$ в 2-3 раза меньше, чем подвижность электронов в образцах, легированных только фосфором. Также следует отметить, что концентрация электронов в образцах, легированных только фосфором, почти на порядок больше, чем концентрация электронов в образцах, легированных фосфором и галлием.

При этом также следует отметь следующий интересный факт, связанный с образованием комплексов $\left[\mathrm{P}^{+} \mathrm{Ga}^{-}\right]$, которые находятся в соседних узлах решетки кремния. При образовании таких комплексов в решетке формируются новые бинарные электрически нейтральные решетки типа $\mathrm{Si}_{2} \mathrm{P}^{+} \mathrm{Ga}^{-}$(рис. $4, b$ ).

\section{5. Заключение}

В работе показано, что в кремнии, предварительно легированном высокой концентрацией фосфора, при диффузии галлия происходит существенное увеличение растворимости галлия. Полученные результаты объясняются взаимодействием атомов галлия и фосфора, в результате которого, формируются квазинейтральные молекулы $\left[\mathrm{P}^{+} \mathrm{Ga}^{-}\right]$. Предположено, что образование таких квазинейтральных молекул $\left[\mathrm{P}^{+} \mathrm{Ga}^{-}\right]$стимулирует формирование бинарных элементарных ячеек $\mathrm{Si}_{2} \mathrm{GaP}$ в решетке кремния. Формирование этих бинарных элементарных ячеек с достаточно высокой концентрацией, и изучение их влияния на фундаментальные параметры кремния представляют большой практический и научный интерес.

\section{Конфиликт интересов}

Авторы заявляют об отсутствии конфликта интересов.

\section{Список литературы}

[1] G.W. Ludwig, H.H. Woodbury, R.O. Carlson. J. Phys. Chem. Sol., 8, 490 (1959).

[2] J. Kreissl, W. Gehlhoff. Phys. Status Solidi B, 145, 609 (1988).

[3] М.Г. Мильвидский, В.В. Чалдышев. ФТП, 32 (5), 513 (1998).

[4] M.K. Bahadirkhanov, B.K. Ismaylov, K.A. Ismailov, N.F. Zikrillaev, S.B. Isamov. Int. J. Adv. Sci. Techn., $29(9), 6308$ (2020).

[5] M.K. Bakhadyrkhanov, K.S. Ayupov, G.Kh. Mavlyanov, S.B. Isamov. Semiconductors, 44 (9), 1145 (2010).

[6] М.К. Бахадирханов, Б.А. Абдурахманов, Х.Ф. Зикриллаев. Приборы, 5 (215), 39 (2018).

[7] M.K. Bakhadyrkhanov, Kh.M. Iliev, G.Kh. Mavlonov, K.S. Ayupov, S.B. Isamov, S.A. Tachilin. Techn. Phys., 64 (3) 385 (2019).

[8] M.K. Bakhadyrhanov, U.X. Sodikov, Kh.M. Iliev, S.A. Tachilin, Tuerdi Wumaier. Mater. Phys. Chem., 1, 89 (2019). 
[9] Л.И. Гречихин, С.Д. Латушкина, В.М. Комаровская, Ю. Шмермбекк. Упрочняющие технологии и покрытия, 9, 5 (2015).

[10] M.K. Bakhadirkhanov, Sh.I. Askarov, N. Norkulov. Phys. Status Solidi A, 142, 339 (1994).

[11] E.M. Conwell. Proc. IRE, 46 (6), 1281 (1958).

[12] A. Florakis, T. Janssens, N. Posthuma, J. Delmotte, B. Douhard, J. Poortmans, W. Vandervorst. Energy Procedia, 38, 263 (2013).

[13] E. García-Tabarés, D. Martín, I. García, I. Rey-Stolle. Sol. Energy Mater. Sol. Cells, 116, 61 (2013).

[14] Л.Н. Александров, Т.В. Бондарева, Г.А. Качурин, И.Е. Тысченко. ФТП, 25 (2), 227 (1991).

[15] Д.С. Королев, А.Н. Михайлов, А.И. Белов, В.К. Васильев, Д.В. Гусейнов, Е.В. Окулич. ФТП, 50 (2), 274 (2016).

[16] T. Ahlgren, J. Likonen, J. Slotte, J. Raisanen, M. Rajatora, J. Keinonen. Phys. Rev. B, 56 (8), 4597 (1997).

[17] Е.Г. Тишковский, В.И. Ободников, А.А. Таскин, К.В. Феклистов, В.Г. Серяпин. ФТП, 34 (6), 655 (2000).

[18] Г.В. Гадияк. ФТП, 31 (4), 385 (1997).

Редактор А.Н. Смирнов

\section{Effect of the presence of a sufficiently high phosphorus concentration on the concentration distribution of gallum in silicon}

M.K. Bakhadirkhanov, N.F. Zikrillaev, S.B. Isamov, Kh.S. Turekeev, S.A. Valiev

Tashkent State Technical University, 100095 Tashkent, Uzbekistan

Abstract It was found that the silicon preliminarily doped with a high concentration of phosphorus during the diffusion of gallium, there is a significant increase in the solubility of the gallium. The results obtained are explained by the interaction of gallium and phosphorus atoms, as a result of which quasi-neutral molecules $\left[\mathrm{P}^{+} \mathrm{Ga}^{-}\right]$are formed. It is assumed that the formation of such quasineutral molecules $\left[\mathrm{P}^{+} \mathrm{Ga}^{-}\right]$stimulates the formation of $\mathrm{Si}_{2} \mathrm{GaP}$ binary unit cells in the silicon lattice. It is shown that a sufficiently high concentration of such unit cells can lead to a significant change in the electrophysical parameters of silicon, i. e. the possibility of obtaining a new material based on silicon. 